\title{
Undertaking Educational Research Following the Introduction, Implementation, Evolution, and Hybridization of Constructivist Instructional Models in an Australian PBL High School
}

\author{
Adam Hendry \\ Parramatta Marist High School, ahendry@parra.catholic.edu.au \\ Gavin Hays \\ Catholic Education, Diocese of Parramatta, Australia, ghays@parra.catholic.edu.au \\ Kurt Challinor \\ Catholic Schools Office, Diocese of Lismore, Australia, kchallinor@lism.catholic.edu.au \\ Daniel Lynch \\ Newman College, Perth, Lynch.Daniel@cathednet.wa.edu.au
}

IJPBL is Published in Open Access Format through the Generous Support of the Teaching Academy at Purdue University, the School of Education at Indiana University, and the Jeannine Rainbolt College of Education at the University of Oklahoma.

\section{Recommended Citation}

Hendry, A. , Hays, G. , Challinor, K. , \& Lynch, D. (2017). Undertaking Educational Research Following the Introduction, Implementation, Evolution, and Hybridization of Constructivist Instructional Models in an Australian PBL High School. Interdisciplinary Journal of Problem-Based Learning, 11(2).

Available at: https://doi.org/10.7771/1541-5015.1688

This document has been made available through Purdue e-Pubs, a service of the Purdue University Libraries. Please contact epubs@purdue.edu for additional information.

This is an Open Access journal. This means that it uses a funding model that does not charge readers or their institutions for access. Readers may freely read, download, copy, distribute, print, search, or link to the full texts of articles. This journal is covered under the CC BY-NC-ND license. 


\section{Undertaking Educational Research Following the Introduction, Implementation, Evolution, and Hybridization of Constructivist Instructional Models in an Australian PBL High School}

\section{Cover Page Footnote}

The authors would like to acknowledge the ongoing support of their principal, Brother Patrick Howlett, FMS; their doctoral studies' supervisors, Professor Henk Schmidt, Erasmus Universiteit, Rotterdam, and Dr Jerome Rotgans, Lee Kong Chian School of Medicine at Nanyang Technological University, Singapore; and their colleagues at Parramatta Marist High, NSW, Australia. 


\section{THE INTERDISCIPLINARY JOURNAL OF PROBLEM-BASED LEARNING}

\section{SPECIAL ISSUE ON COMPETENCY ORIENTATION IN PROBLEM-BASED LEARNING: VOICES FROM THE FIELD}

\section{Undertaking Educational Research Following the Introduction, Implementation, Evolution, and Hybridization of Constructivist Instructional Models in an Australian PBL High School}

Adam Hendry* (Parramatta Marist High School); Gavin Hays (Catholic Education, Diocese of Parramatta, Australia) and Kurt Challinor (Catholic Schools Office, Diocese of Lismore, Australia); and Daniel Lynch (Newman College, Perth)

\section{Abstract}

The aim of this paper is to provide an overview of the introduction, implementation, evolution, hybridization, and initial research into the constructivist instructional models deployed within a secondary (high) school in Australia. A concomitant aim is to relate some of the consequences of whole school pedagogical change, which have included the implementation of project- and problem-based learning, the flipped classroom, and a derivative hybridized form, referred to here as "flipped PBL." Moreover, after a decade of using constructivist approaches, we initiated educational research to better understand some of the effects of these changes and to explore the reasons behind the successful implementation of the models. While still in its infancy, the nature of this research and some of the preliminary findings are detailed here.

Keywords: problem-based learning, project-based learning, flipped classroom, flipped PBL, constructivist, student-centered learning

Over the last decade, Parramatta Marist High School, a Catholic non-selective boy's secondary school in Western Sydney, Australia, has undergone substantial whole school pedagogical change. In 2008, project-based learning was adopted in the middle school curriculum (year 9 and then year 10). Subsequently, a problem-based learning approach, derived from the "One Day, One Problem" model pioneered at Republic Polytechnic (RP), Singapore, was adopted as these students moved into their penultimate year of schooling, year 11 (Alwis \& O'Grady, 2002). In 2013, a "flipped classroom" approach was introduced for final year students, and in 2016, the "One Day, One Problem" approach was refined into a flipped PBL model. The intention in undertaking this fundamental shift toward constructivist pedagogies was to increase student engagement and to explicitly teach, model, and assess important "soft" or $21^{\text {st }}$ century skills needed beyond school, while maintaining academic rigor. In that time, the school's performance in statewide standardized exit exams has improved considerably, peaking at $43^{\text {rd }}$ in the state in 2014, and with every subject being above state average and reaching $4^{\text {th }}$ in the state in Mathematics in 2016. After almost a decade, it was deemed an opportune time to undertake educational research to better understand what effects of

${ }^{*}$ Corresponding author

This paper was presented in a panel discussion at PBL2016 in Zurich, Switzerland. 
this change, if any, can be determined, and also offer means for improvement of the models deployed within the school.

Consequently, in 2015, we commenced doctoral studies under Professor Henk G. Schmidt of Erasmus University, cosupervised by Assistant Professor Dr. Jerome I. Rotgans, Lee Kong Chian School of Medicine at Nanyang Technological University, Singapore, in an attempt to better understand some of the multifarious effects of whole school pedagogical change following the introduction, implementation, evolution, and hybridization of constructivist instructional models deployed within the school. Furthermore, we formed a research partnership with experienced researcher in cognitive load theory and group dynamics Dr. Jose Hanham, from Western Sydney University, to pursue other related research areas within the school.

\section{Intentions and Challenges in Implementing Constructivist Instructional Models at Parramatta Marist}

A continual and overarching intention of all the constructivist instructional models currently employed at Parramatta Marist is to develop the whole learner for both now and the future within what is the most technologically rich age in human history. Hence, the learning attempts to emulate the environment encountered by professionals in their disciplines with the intention of increasing engagement and improving the practical and/or applied skills of students. Theoretically, by making the classroom more reminiscent of the "real world," students are encouraged to undertake projects and solve problems like a professional in a particular discipline. Critical to this process is the activation of prior knowledge and engaging with new knowledge, both of which are fundamental in order to solve problems that are new to the learner, as is the role of the teacher as a facilitator and one who can stimulate the process of inquiry leading to new knowledge. Additionally, these models afford students an opportunity for greater self-direction within a safe learning environment that is heavily scaffolded and commensurate with the age of participants, and therefore not minimally guided.

If we set aside the frequent debates surrounding the differences between project- and problem-based approaches to learning (Savery 2006) and their suitability to differing disciplines (Perrenet, Bouhuijs, \& Smits, 2000), we can see that both PBL approaches afford students the opportunity to collaborate with peers, and develop interpersonal communication, reporting, and presentation skills, as well as problemsolving and critical thinking skills (Schmidt, van Der Molen, te Winkel, \& Wijnen, 2009). Similarly, the flipped classroom places the student at the center of the learning process and draws upon those elements discussed above that are relevant to that approach. All of the constructivist instructional models employed at Parramatta Marist since 2008 have emphasized the primacy of knowledge acquisition and its application with potentially beneficial by-products variously described as "soft," " $21^{\text {st }}$ century," or "enterprise skills."

The reasons for introducing each of these models, and their associated challenges, consequences, and development, are discussed below.

\section{Project-Based Learning (2008-Present)}

The initial reasoning behind the implementation of projectbased learning was twofold. First, the millennial-era debate surrounding the relevance of traditional approaches to teaching and learning in the age of the Internet and exponential growth of technology was building momentum within the national educational context, resulting, ultimately, in the launch of the Australian government's Digital Education Revolution (DER) in 2007. The DER aimed at increasing the use of information and communication technology (ICT) within Australian classrooms, and it provided laptops to all students in years 9-12 as well as the resources and support for teachers in implementing their use. Second, and closer to home, there was a noticeable lack of engagement among students in the middle high school years (years 9 and 10; ages 14-16), according to school staff. The impression that these students were the most disengaged within the school was subsequently borne out by Jenkins (2012), whose survey of over 2,000 teachers in the United States found this grade/age group the most disengaged overall. It was within this educational milieu that a study tour, led by members of the school executive (comprising the principal and assistant principals), of the Napa New Tech High School (in the United States) in early 2007 resulted in the decision to implement projectbased learning (PBL) in year 9 for the 2008 academic year (starting in January in Australia). This visit to Napa also led to the establishment of links (and later the formalized partnership) with the New Tech Network, a not-for-profit foundation that provides training and ongoing support for over 200 PBL schools in the United States and Australia. Resources, in the form of planning time and professional development, were allocated to a group of around ten teachers or "early adopters" to ensure that the implementation was successful. The group attended PBL training in the United States to gain a deeper understanding of effective PBL practices. Projectbased learning at Parramatta Marist was initially deployed across the middle school curriculum in every key learning area (KLA) with the exception of some electives and accelerated courses (e.g., mathematics), but was later rolled back into years 7 and 8 in 2013, when teaching capacity could fully support this move. Complementary subjects were and remain integrated, and multidisciplinary projects are created 


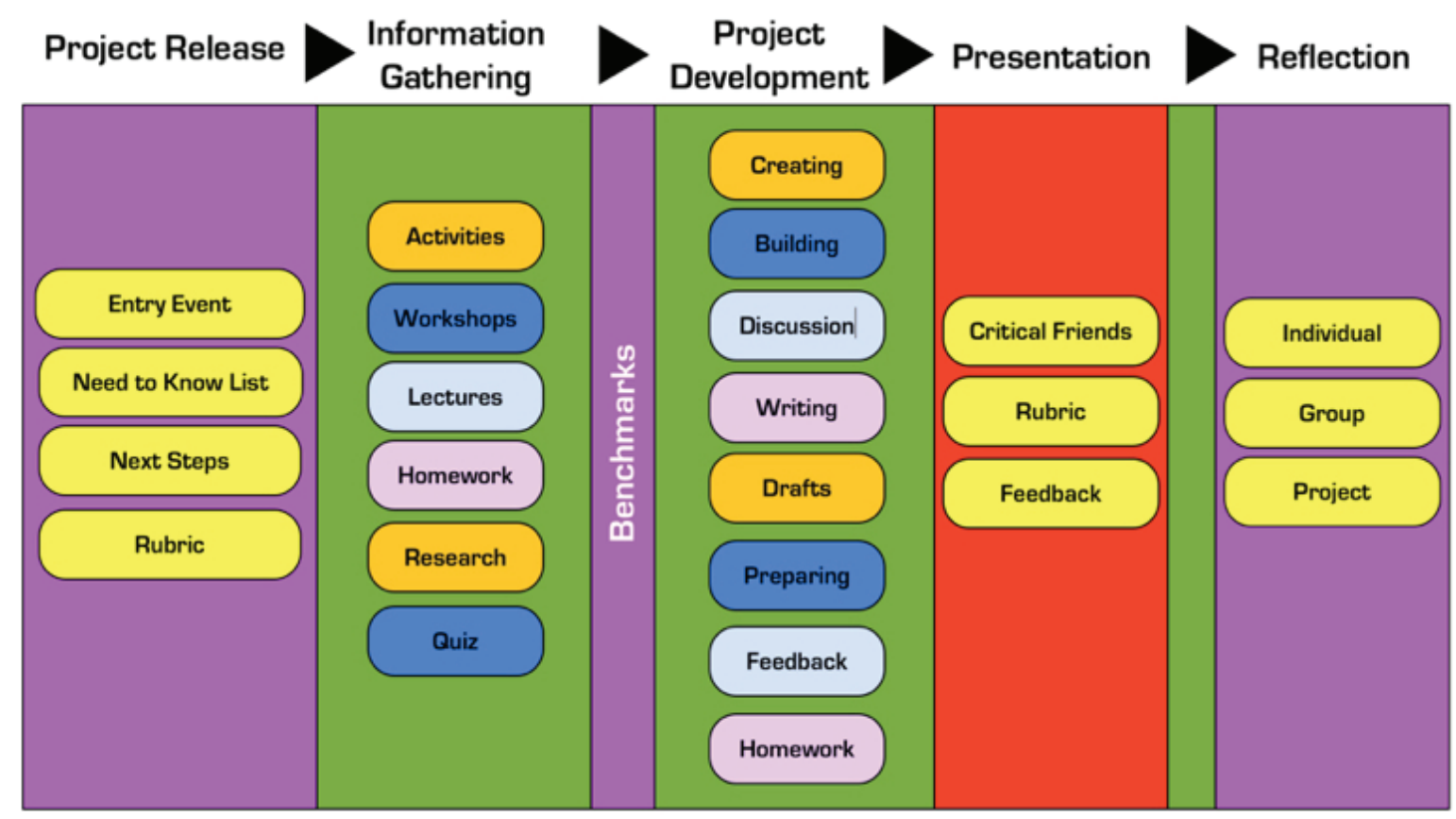

Figure 1. Project-based learning as implemented in years 7-10 at Parramatta Marist High (source: Gavin Hays).

when syllabus outcomes or aims align. This integration of subjects (e.g., history and English) resulted in the identification of the need to develop team-teaching practices with colleagues from different disciplines, and also led to a rethink of the available learning spaces. Consequently, to prepare for the change to PBL, six individual classrooms were combined to form three double-sized classrooms to accommodate one teacher and one class from each integrated discipline. The model follows the process shown in the infographic displayed above in Figure 1.

A project is released to the students through an "entry event," which provides an authentic trigger detailing what students must create at the culmination of the project. Students then have an opportunity to identify what they know and do not know in order to commence the project. As a living document, this "need-to-know" list is amended and developed throughout the project and should provide students with direct links to the targeted curriculum. These documents along with the assessment rubric help to guide the process of inquiry. Furthermore, students are assessed throughout the project in myriad ways, including individually and/or as a group, formatively and summatively, and informally and formally; they are also afforded opportunities to assess their peers specifically in collaboration. A multiplicity of scaffolding and resources are offered to the students to both differentiate and enhance the learning; however, the most important resource in the room remains the teacher, albeit now as a facilitator. Projects typically last between 5-10 weeks with students working in mixed ability groups to achieve a range of formative benchmarks that assist the construction of their summative end product. In the initial phase, the learning management system (LMS) utilized was Moodle; however, as the connection with the New Tech Network grew and was formalized, their purpose-built (for PBL) learning management system, known as "Echo," was adopted.

Some of the initial reactions to the introduction of $\mathrm{PBL}$ from the school community were centered on the impact of an instructional approach that also focused on the teaching, modeling, and assessing of skills as well as the content. However, once the assessment strategies were articulated and aligned to the projects in a way that was clearer to all stakeholders, there was little resistance, which in itself was surprising given the school was not failing but was not necessarily outperforming other similar schools.

\section{Project Example- "In the Shadows of the Shoah"}

An exemplary project undertaken centers on an integrated study of the Second World War, the Holocaust, and John Boyne's historical novel The Boy in the Striped Pyjamas. This 10 -week project is targeted at year 9 students (14-15 year olds) and integrates content and skills from the domains of English and history. The authentic trigger or driving question underpinning the project is: "How can we, as museum curators, design and construct an interactive exhibition that 


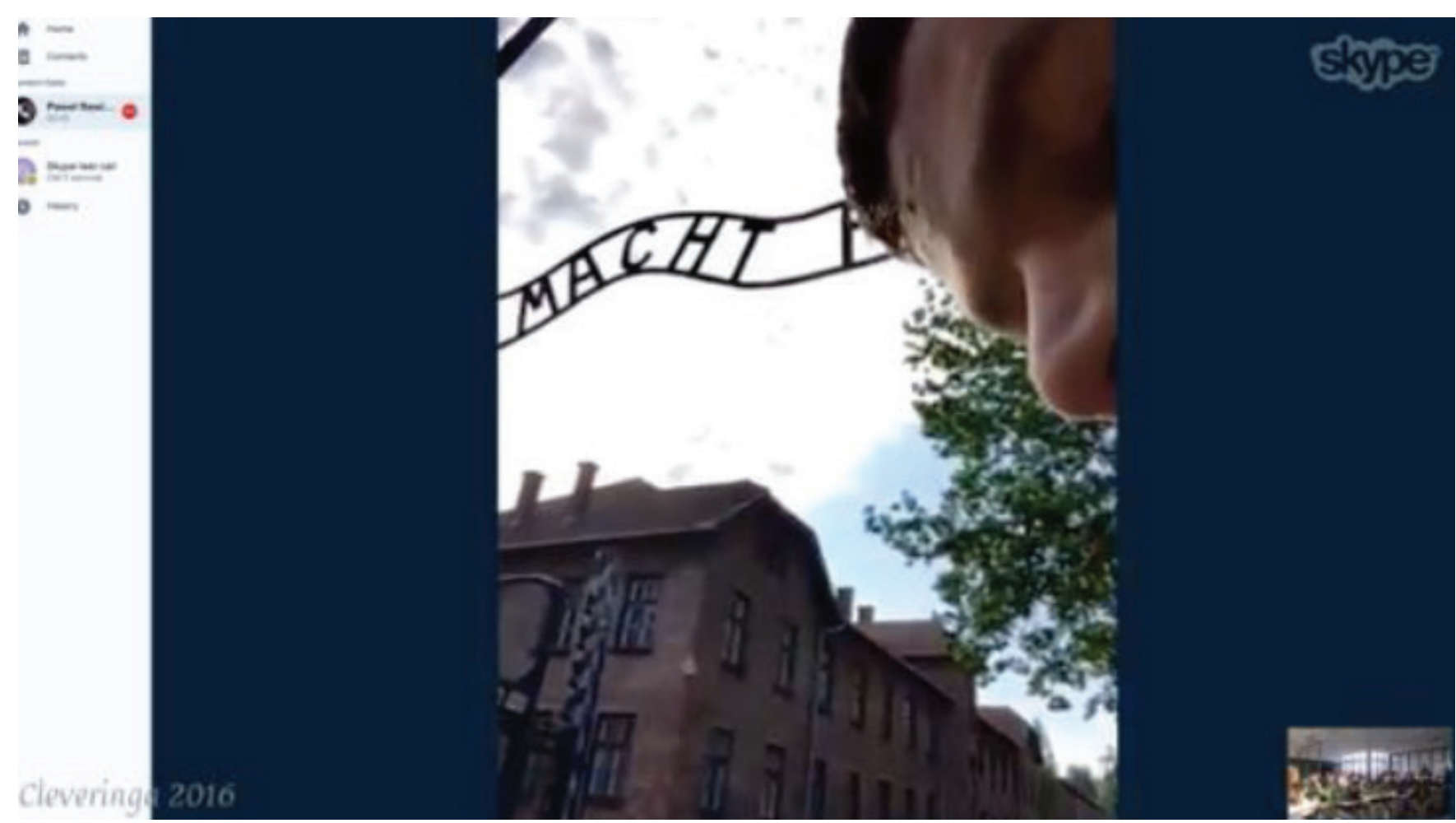

Figure 2. Skype interview with Pawel Sawicki (source: Maddie Cleveringa).

presents a narrative of the experiences of those who endured the Shoah, so that visitors understand its impact?"

From the outset, this project was designed to enhance students' ability to apply their understanding of literary terms and techniques to their own writing through engaging with the novel, simultaneously pursuing a historical study of the Holocaust and war years in order to understand the context and setting more deeply.

The project also provided an opportunity for students to gain formative feedback from teachers as they prepared their summative end product-a museum exhibit. First, students constructed a historical narrative about an imagined personal experience throughout (and beyond) the Second World War that demonstrated a strong understanding of the context of the characters within the novel through the inclusion of primary and secondary historical sources. Many of the stories developed by students were based on the real experiences from survivors who had migrated to Australia, contact with whom (and other survivor stories) had been learned or facilitated through the Sydney Jewish Museum.

Second, students participated in a Skype discussion with Pawel Sawicki from the Auschwitz Concentration Camp Memorial in Poland (shown in Figure 2). Students were given the opportunity to interview Pawel to gain insights into the Holocaust and a deeper understanding of the realities of war as he took them on a virtual tour of the infamous concentration camp. Furthermore, students undertook a comparative study of the novel and film version and investigated related texts such as Anne Frank's diary and Rose Blanche by Ian McEwan and Roberto Innocenti. As a consequence of these experiences, students were better able to empathize with Holocaust victims and convey emotion through more vivid imagery and descriptive language in their narratives and, subsequently, their museum exhibits.

Finally, the summative task challenged students to combine their individual formative task into one continuous narrative that explored more thoroughly the life of Jewish victims, prisoners of war, and German soldiers and prison guards. Each group planned, researched, and designed a realistic museum narrative trail exhibiting a variety of artifacts created with software such as Adobe Photoshop and Aurasma (an augmented reality app). Furthermore, students had access to 3-D printers and laser cutters in the school's fabrication laboratory (FabLab) to help create physical artifacts leading to the curation of some outstanding museum exhibits as shown in Figure 3 (next page). Overall, this project provided students with an opportunity to explore and display deeper interdisciplinary content knowledge (as shown in Figure 4, next page), while the authentic links to real-world learning afforded them the opportunity to enhance their skills in collaboration, communication, and critical thinking.

\section{Problem-Based Learning (2010-2015)}

As the initial group of PBL-trained students entered year 10 and moved toward their penultimate year of schooling, they 


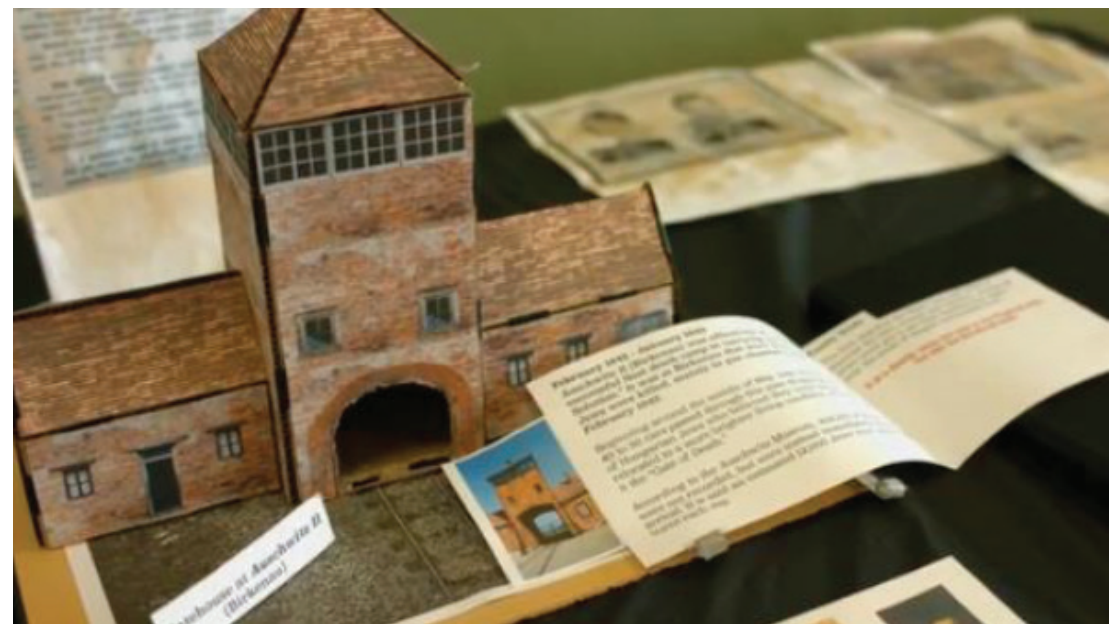

Figure 3. Use of different methods to construct the museum artifacts (source: Kurt Challinor).

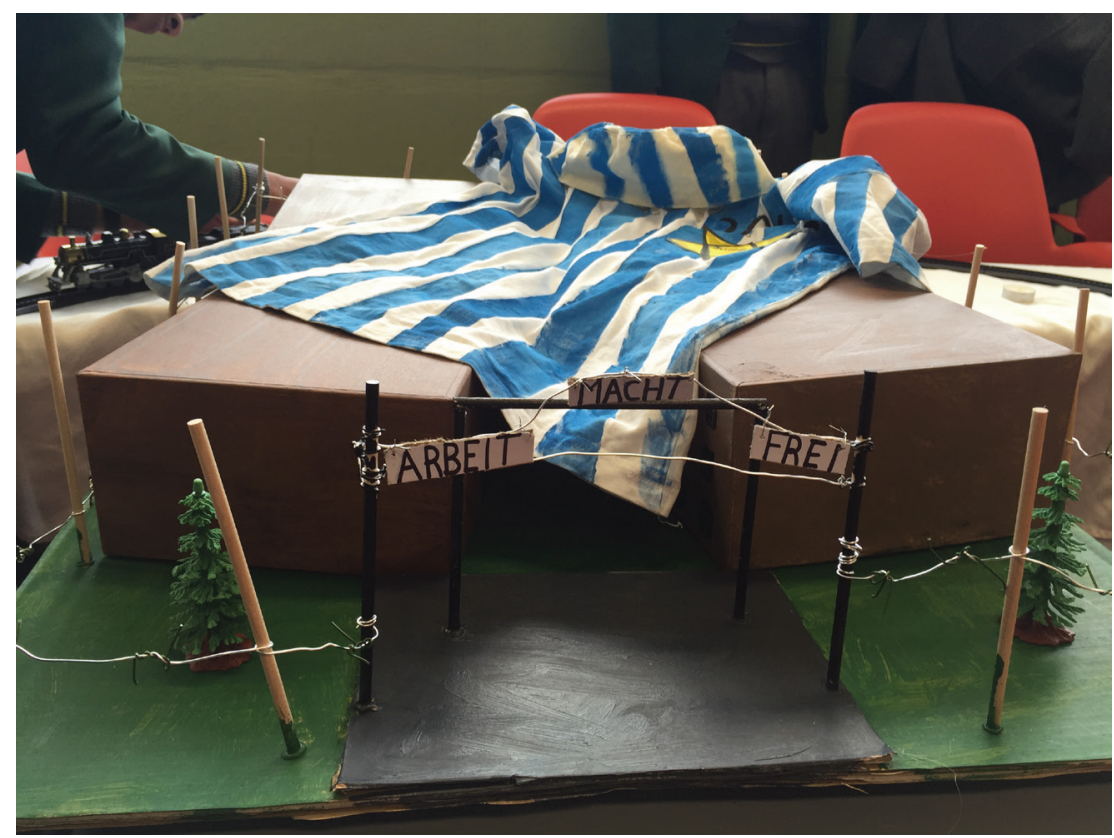

Figure 4. Overall snapshot of an exhibit (source: Kurt Challinor).

began to raise questions regarding what the teaching and learning would like for them in year 11. A reference group composed of students, teachers, and members of the school executive convened. There was a feeling that the preliminary courses for the New South Wales (NSW) Higher School Certificate (HSC) would not lend themselves easily to projectbased learning due to the state-sponsored syllabi being very content heavy and too restrictive. In 2009, another overseas study trip offered one possible solution. Members of the reference group, including one of the authors, encountered the "One Day, One Problem" model pioneered at Republic Polytechnic, Singapore (see Rotgans, O'Grady, \& Alwis 2011).
The structuring of this model was appealing as it could offer a more focused look at aspects of the curriculum while continuing to build on those soft skills developed by students in years 7-10. Consequently, the "One Day, One Problem" model was adopted across almost all courses (except some vocational educational training courses); however, to meet the indicative course hours required by the New South Wales Board of Studies, Teaching and Educational Standards (BOSTES), the Republic Polytechnic approach was adapted to what became known as the "1-5-1" PBL model. This designation was descriptive of the break-up of hours within a learning module over a biweekly timetable cycle. In general, 
Table 1. "1-5-1" problem-based learning model structure (2010-2015).

\begin{tabular}{ll}
\hline Contact hours & Teaching and learning activities \\
\hline $\mathbf{1 ~ H o u r}$ & Pre-quiz \\
(First contact) & Brainstorm that activates prior knowledge \\
& Direct instruction to introduce concepts or ideas \\
& Scaffolded activities \\
& Utilize a text (often created online or in iBook by staff) \\
& Check homework set \\
& Problem statement release \\
(Full-day) & Know/Need-to-know list \\
& Group work on problem \\
& Facilitation of problem \\
& Scaffolded activities (optional) \\
& Worksheets (paper or online) \\
& Group presentations \\
& Facilitator presentation of one potential solution \\
& Reflection journal \\
& Evaluation \\
& Post-module quiz \\
& Class discussion on syllabus points and link to problem \\
& Direct instruction \\
& Assessment (e.g., exam-style question) \\
\hline
\end{tabular}

each course had 13 biweekly learning modules into which the traditionally structured course curriculum was repackaged into open-ended and ill-structured problems (although this was dependent on the syllabus requirements of each course). Student learning in the 1-5-1 PBL model was initially supported through a Moodle-based LMS (with students using school owned laptops) tailored to the needs of the model; however, this was changed to Apple iTunesU when iPads were subsequently adopted. The structure and associated teaching and learning activities that were typically undertaken within that model are shown in Table 1.

To ensure the crafting of quality problems, the effective facilitation of modules and curriculum (re-)design, teaching staff participated in intensive professional learning programs delivered by members from Republic Polytechnic's Centre for Educational Development-something ordinarily offered to Polytechnic academic staff as part of their training. School staff have regularly attended this intensive training, based in Singapore, since 2009.

The 1-5-1 structure initially met the needs of the students by continuing to expose them to (and report on) critical skills like problem solving, teamwork, presentation, and communication while engaging with more sophisticated content. This model was in place between 2010 and 2015 until the introduction of the flipped classroom approach (described below) provided some insights as to how to better address those unforeseen consequences of the introduction of this model (also described below).

\section{The Flipped Classroom (2013-Present)}

In late 2012, a "flipped classroom" approach was introduced for final-year high school students (year 12) completing their New South Wales (NSW) Higher School Certificate (HSC) in 2013. This is the standardized exit exam that universities use to determine entries into their courses. While there is no one single, generally accepted definition for the flipped classroom, the approach can still be broadly described as the shifting of the acquisition of new content and concepts from the classroom to the home (or at least some time prior to the class, often in the form of a video), with class time being used to engage in more student-centered and active learning and the clarification and application of knowledge. All subjects in the HSC utilize the flipped classroom approach to deliver content. The students have course material delivered by a learning management system (Apple's iTunesU) through their own devices (iPads). This approach has the potential to offer a number of benefits. The transferring of some content delivery beyond the classroom as homework, particularly through the use of technology, frees 
class time for instructors to engage students in active learning experiences that have the potential to increase engagement and differentiation while providing an environment where student self-efficacy can develop and where students can become more self-directed learners. Additionally, the move to the flipped classroom approach also offered a solution to better deliver competency-based vocational educational training courses that were, due to the nature of their content and assessment, difficult to problematize.

\section{A Hybridized Model-“Flipped” PBL (2016)}

The 1-5-1 PBL model was successfully utilized between 2010 and 2015, but two major issues arose as a consequence of its implementation, specifically (a) the model reduced the flexibility of the timetable and consequent staffing, and (b) it became evident that students required more time to process information and apply their understanding (and devise solutions) in subjects with very content-rich syllabi. Two further developments within the school, however, occasioned an opportunity for the evolution of the model to address its perceived deficiencies and effects. First, the very successful introduction of the flipped classroom approach in 2013 for HSC students opened greater opportunities to deliver content before the class and spend contact hours clarifying and applying what had been learned. The evolution of the 1-5-1 model was also facilitated by a second development, the instigation of a "bring your own device" (BYOD) program across the school. This now meant content could be delivered to personal devices prior to the commencement of the first class in a (new) biweekly year 11 "flipped PBL" module; ultimately, giving students the opportunity to watch an introductory video or other stimulus material and engage with the content prior to meeting with their facilitating teacher. This also now meant that both approaches to learning in the senior school could also be accommodated by Apple's iTunesU LMS on student-owned iPads.

Moreover, rather than grappling with a problem and presenting a solution in one day, students are now required to present during a subsequent period and are thus afforded an interim period of self-study and collaboration (both online and in their own time at school) with group members. The structuring of this "flipped PBL" model, a term gaining some currency and similar approaches being adopted in other academic settings (Tawfik \& Lilly, 2015), is shown in Figure 5. Thus, problem-based learning at Parramatta Marist has evolved over the last seven years in response to the needs of students, staff, and the school environment, as well as to developments within and without the school to ensure it remains a dynamic and innovative pedagogy.

\section{Problem Example-“UBER”}

The following problem is indicative of how the state-sponsored curricula are problematized to engage the learners while still

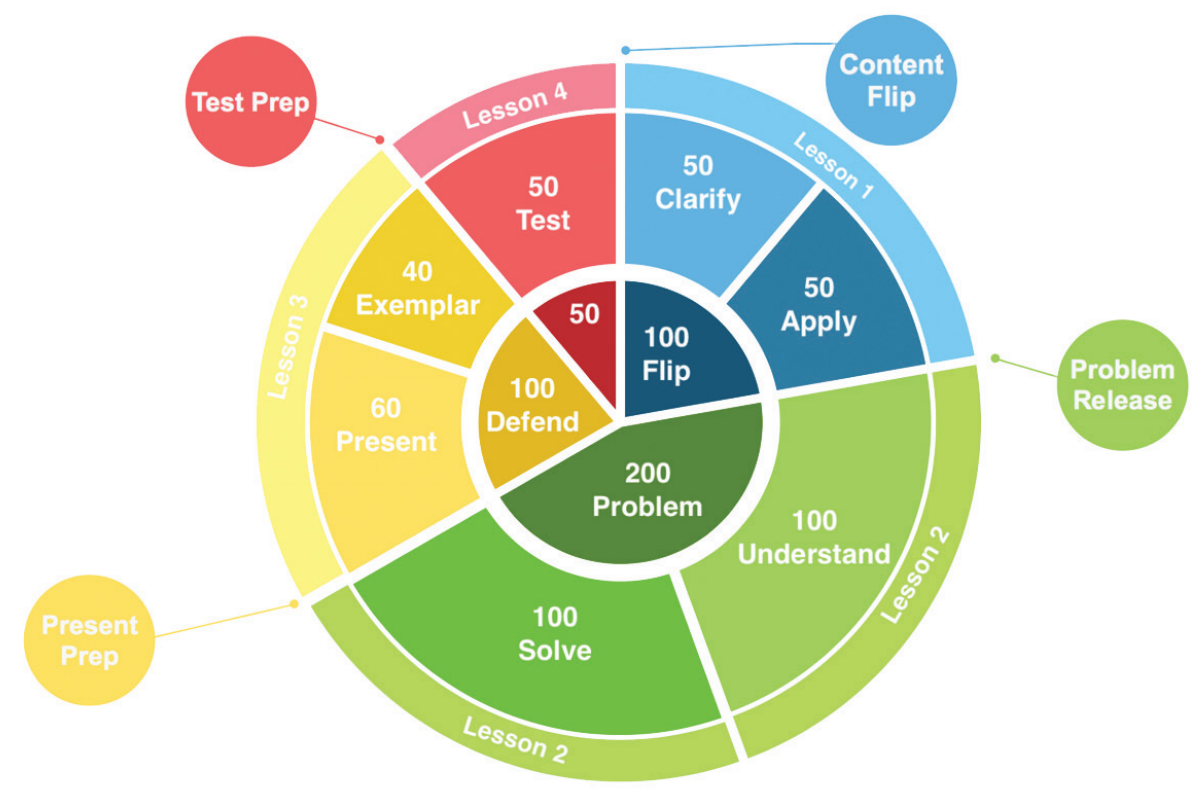

Figure 5. Flipped PBL in year 11 as of 2016 (source: Kurt Challinor).

Note: The color coding in Figure 5 denotes the sequence and timing of sessions in one module within a biweekly timetable cycle. Therefore, following the flipped content pre-learning session timings are 100 (blue), 200 (green), 100 (yellow), and 50 (red) minutes across four different days. 
placing an emphasis on soft skills acquisition and assessment. In this instance, the taxi ride-sharing service UBER offers students a contemporary business case study to explore the idea of internal and external influences on businesses within a particular environment. This problem was used in the second biweekly module in the year 11 preliminary HSC business studies course. In the hybridized model introduced in 2016 (outlined above), students engage, initially, with flipped content prior to the first lesson in the cycle (in this case, a video on the potential impacts on a business of internal and external influences in the business environment) and respond to questions that are submitted online to the teacher. Further exploration of the targeted content is explored in the "Flip: Clarify and Apply" stage, where the teacher addresses gaps in the students' knowledge. Students are also asked to apply what they know (for example, by engaging with other case studies that are generally dissimilar to UBER) and respond to stimulus material and participate in scaffolded activities using contemporary and relevant examples to ascertain the level of their understanding with the ultimate aim of ensuring that students have a good grounding in the content prior to the release of the problem in the subsequent lesson.

At the commencement of the "Problem: Understand and Solve" stage in the cycle, the UBER case study is released with the following problem statement: "Which one internal and one external influence will have the most impact on UBER's success in the Australian market?" At this point, students have an opportunity to identify what they know and do not know about the problem in a way that they became familiar with in years 7-10. This need-to-know list helps direct each group through a range of resources, scaffolded activities, and workshops (both teacher- and student-led) during this stage. This is followed by a period of self-study (and online collaboration) between group members to ensure they are ready to present their solution during the next stage of "Defend: Present and Exemplar." Student group presentations are normally expected to last 10 minutes, with a question and answer

\section{INTERNAL INFLUENCE- BUSINESS RESOURCES}

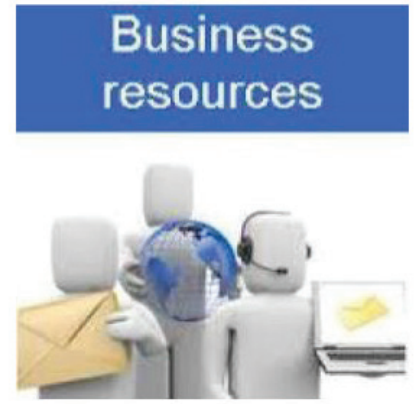

All provided by the driver!

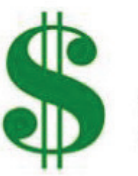

Financial resource

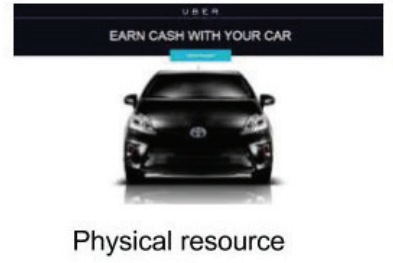

Information resource

Figure 6. Student group solution to UBER problem (source: Adam Hendry).

\section{EXTERNAL INFLUENCE- LEGAL}

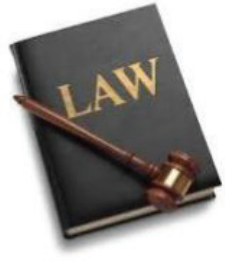

In NSW the Passenger Transport Act 2014 and the Passenger Transport Regulation 2007 apply

Across Australia, commercial

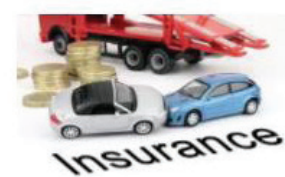
passenger services can only be legally provided if certain requirements are met. Usually this means that the vehicle needs to be properly licensed as a taxi or hire car, and the driver has to be accredited as a taxi or hire car driver

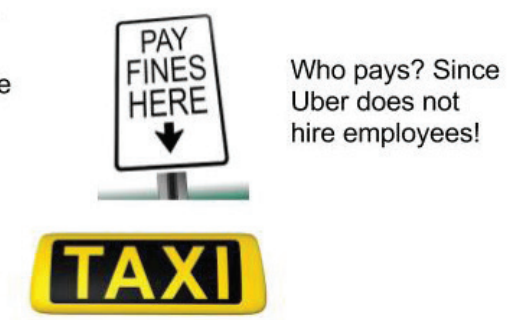

Competition \& Consumer Act 2010 prohibits any activity that impacts on fair competition!

Figure 7. Student group solution to UBER problem (source: Adam Hendry). 
session immediately following the presentation. An example of the visual aids used to support a student solution to the UBER problem statement is provided in Figures 6 and 7.

Student solutions are marked using a standardized rubric that is structured in the following way: 12 marks for application of content in the problem solution; three marks for presentation; three marks for another nominated soft skill that is most suitable to that particular problem (e.g., numeracy); and two nominal marks awarded for the completion of two evaluations (one on the module, one on its facilitation). Following the completion and marking of group presentations, the teacher/facilitator presents an "exemplar" that offers one possible (and informed) solution to the problem statement. The final phase of the cycle requires students to apply their knowledge under conditions reminiscent of more formalized testing in that discipline. In this particular problem, students are asked to prepare a business report addressing the following: "Using your own knowledge and relevant business case studies, discuss why it is critical for owners to be aware of the impact of internal and external influences on their business." Naturally, some course syllabi lend themselves more easily to being problematized. In this instance, the dynamism of the world's business environment ensures problems can remain evergreen with the update of a relevant and contemporaneous case study.

\section{Reflections on Effecting Whole School Pedagogical Change}

Over the last decade, a number of phenomena have been observed regarding the implementation and sustainability of the changes described above. Initially, the scope of our transformational agenda was limited to project-based learning in the context of engaging year 9 students in their learning. However, upon reflection, a number of aspects critical to its success have been identified to develop a coherent transformational framework, as shown in Figure 8.

This transformational framework highlights the key organizational structures as they have developed over the last decade that include the identification and communication of the school's mission and purpose-developing instructional leadership practices, strategic resourcing, and the evolution of our contemporary learning pedagogies. Additionally integrated are the cultural elements that have been essential in maintaining and sustaining overall academic growth. In effecting whole school change, the building of a learning culture or "community" where student-centered educational practices within the school are clearly evident was imperative. Specifically, the language used by both teachers and students is consistently aligned with the mission of the school and the various contemporary learning pedagogies. There

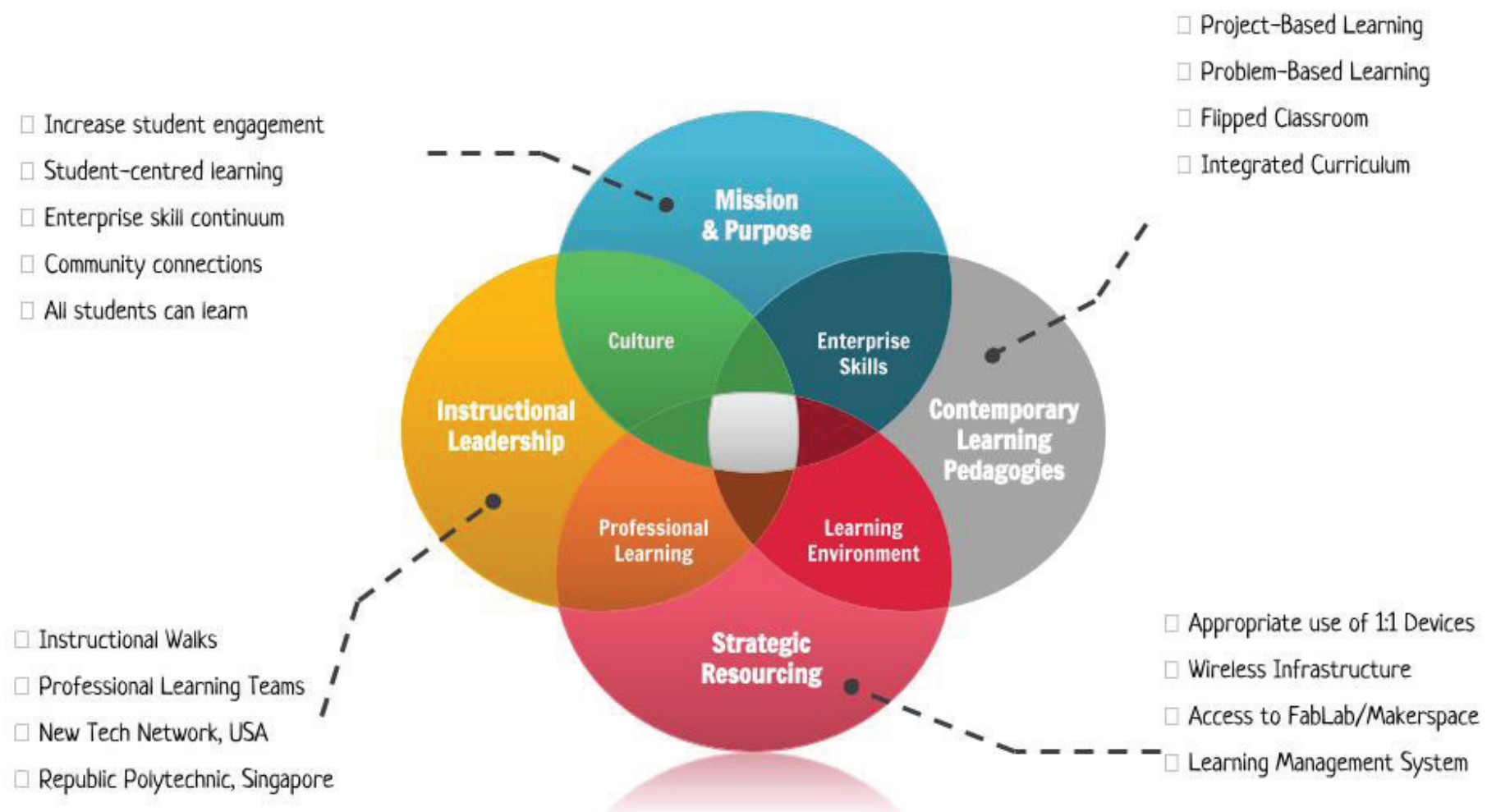

Figure 8. Transformational framework in effecting whole school change (source: Gavin Hays). 
2007

50

40

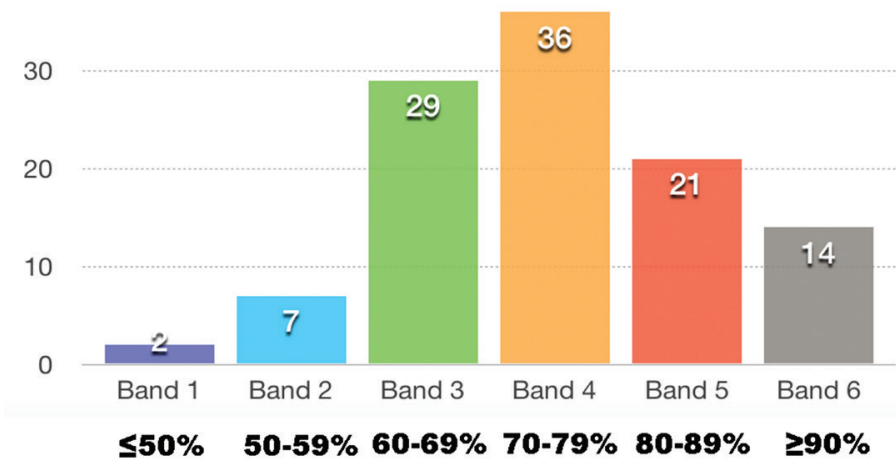

2011

50

40

30

20

10

0

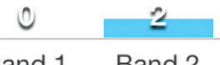

Band 1 Band 2

Band 3

2016

50

40

30

20

10

0

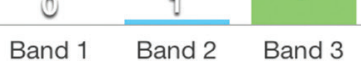

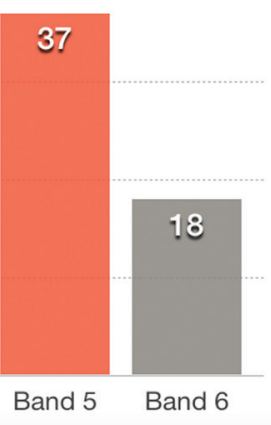

41

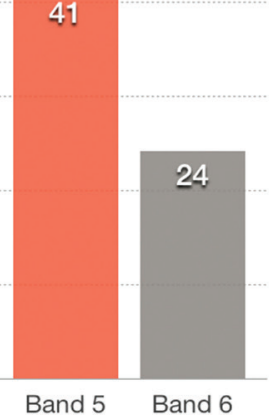

Figure 9. HSC results in all exams per band (\%) in 2007, 2011, and 2015.

is distinct focus on their use of this language, engagement, and participation within the learning process. Moreover, an observable improvement in student enterprise skills, specifically in communication and presentation skills as well as

increased collaboration (particularly online) with peers and teachers, has become the norm for students. Another clear outcome has been the growth in peer-coaching and ability of students to learn at their own pace with the help of teachers.

Another key to learning has been the idea that to effect meaningful change it must occur on a large scale (i.e., not just in one classroom), as these approaches are constrained by the physical, environmental, and educational structures. Strategic resourcing involved creating enabling opportunities to support and sustain the changes through the implementation of an extensive professional development program for staff, which in itself can only be offered to an entire teaching staff. This has meant the introduction of timetabled professional learning periods for staff (often in interdisciplinary professional learning teams). As of 2017, this professional learning amounts to 320 minutes every two weeks. This has afforded all staff the opportunity to continue their professional growth and time to embrace the pedagogical changes taking place in the school. Moreover, both structural and procedural changes were made within the school to accommodate these pedagogical approaches (e.g., timetable changed to three 100-minute lessons a day), and the school established local, national, and international connections in the pursuit of world's best practice. Furthermore, the creation of a flexible learning environment was required to support the culture created through providing organic opportunities for students to collaborate with peers and share ideas. Over the past decade, these approaches to learning and the philosophy that underpins them have become the norm within the school environment.

There have been, and there remain, however, many challenges to the ongoing effective implementation of these approaches. First, in the development of projects and problems to drive the learning, the first obstacles are mandatory, content-rich syllabi that by their very design suppose knowledge is delivered to and not acquired by students. One way this challenge has been addressed is through the integration of complementary subjects and the development of crosscurricular projects that have helped minimize duplicate or redundant content. Second, ensuring teacher training is effective, relevant, and meaningful is also a challenge and, hence, over the last 10 years it has become necessary to provide differentiated professional development to staff, especially in areas of assessment reform, personalized learning, and enhancing the quality of teaching practices. This ongoing, timetabled, comprehensive, and cross-curricular professional development of staff has been crucial in the implementation of these pedagogies (it is true to say that the teacher remains the most important factor in improving educational outcomes for students!). 


\section{Possible Effects of Whole School Pedagogical Change}

There appear to have been multifarious effects of whole school pedagogical change over the last decade. Most interestingly, since the commencement of whole school pedagogical change in 2008, there has been an upward trend in student performance in the HSC results-an external, statewide, standardized exit exam. The data shown in Figure 9 is representative of the demonstrable shift in student achievement toward higher performance "bands" since the approaches to learning were implemented. That is, more students are achieving a band 4 $(70 \%+)$, band $5(80 \%+)$, and band $6(90 \%+)$ in all exams at the HSC each year. In particular, since 2008, there has been significant growth among students at the lower end, with band $1(\leq 50 \%)$, band $2(50 \%+)$, and band $3(60 \%+)$ exam results all but eliminated at the HSC level. To give some context, the number of students taking the HSC every year since 2007 has been 155 (on average), taking an average of 5.5 exams each; this equates to around 850 exams for each cohort every year. Moreover, in 2014, the school was ranked $42^{\text {nd }}$ in the state in the HSC (percentage of band $6 \mathrm{~s}$ achieved versus number of exams taken) and, in 2015, the school was ranked $6^{\text {th }}$ in mathematics in the state; in 2016, it was ranked $4^{\text {th }}$. In the 2015 and 2016 HSC, 95\% students achieved a band 4, 5, or 6 (70$100 \%)$ in all subjects at the HSC exams. Other statewide statistical analyses that compare similar schools at the HSC level (DeCourcy Analyses 2011-2015) against previous performance in standardized state and/or national testing have also revealed that students at Parramatta Marist have consistently achieved at or above expectation across all courses, with 75\% of subjects taken by students identified as having provided them with a learning gain above that which was expected. For a comprehensive all boys' school with a slightly above average socioeconomic status (SES) rating from the Australian Curriculum, Assessment and Reporting Authority (a measure which was specifically designed to enable meaningful comparisons within the National Assessment Program), these results appear significant; however, the authors realize that identifying the contribution that each of the changes within the school have made (if any) to these results is, at present, quite difficult.

Additionally, to what extent has a sense of collective efficacy-the idea that academic performance by similar students in the same school environment has led to a transfer of confidence beliefs from one year to the next-played a role in the growing performance of successive year 12 cohorts also remains unclear. Moreover, feedback from a recent survey of alumni from graduating cohorts educated in the PBL method indicate that learning in a style that is becoming more prevalent in the tertiary sector has improved their transition and subsequent achievement in courses taken-particularly in areas where PBL is practiced, such as medicine, allied health, and engineering. Another key takeaway is the notion that innovation and the implementation of constructivist approaches to learning are no barrier to success in traditional standardized exit exams, as evidenced by the school's results.

\section{Research Questions and Initiatives}

Growing interest from both within and without the school to better understand the consequences of the changes and to pinpoint and better understand the cause of some of these effects, both real and perceived (anecdotal and/or observable), led to some preliminary action research by staff. It soon became apparent, however, that it was not possible to clearly identify any singular reason for the effectiveness of implementation or the academic success described above without undertaking significant educational research. Conversely, it was recognized, too, that the combination of those factors discussed above (e.g., teacher training, collective efficacy, changes to the learning environment, etc.) were, in their totality, responsible for the successful implementation and improvement of the educational outcomes for students, and that even concerted efforts in educational research may only ever unpick part of this patchwork. It was also conceded there might be no apparent correlation between certain changes and their supposed effects. Regardless, in 2015, we decided to initiate this research. Another initial hope, apart from revealing greater insights and some demonstrable links to specific factors, was that institutional research could also offer some means for improvement within the models.

It was on this basis that we framed and began to explore in depth some research questions in 2016. Some of the possible research questions that arose included the following: How do students build confidence within a PBL setting? Can these feelings of efficaciousness be stimulated within the learning environment? Is there a way to measure the effectiveness of the flipped classroom? How has technology enhanced the learning, and can this be better harnessed to provide more timely diagnostic assessment? What motivates students to achieve, and does the nature of learning play a role? How does motivation influence choice, persistence, and performance within this PBL environment? Is there a more scientific basis on which we can select groups? In addition, what roles have the increased professional learning of staff and the standardization of learning and assessment practices played in improving academic results? Also, how can student skill development be adequately assessed?

Accordingly, we developed specific research questions to form the basis of the microanalytical research approaches we initiated at Parramatta Marist. These foci of the research are 
in the areas of (a) the situational development and measurement of self-efficacy in a PBL environment, (b) the development and validation of a new assessment tool, the cognitive recall test (CRT), (c) the development and validation of a reliable instrument to measure the effectiveness of the flipped classroom approach, and (d) achievement motivation within a PBL environment. Additionally, in partnership with a local university, research into efficacy beliefs is presently underway. This research is attempting, as a starting point, to better understand some critical aspects of whole school pedagogical change. The intentions and nature of the research as well as any preliminary findings are discussed below.

\section{Situational Development and Measurement of Self-Efficacy in a PBL Environment}

According to the Albert Bandura, self-efficacy can be defined as "an individual's assessment of their capabilities to organise and execute courses of action needed to perform certain tasks and is concerned not with the skills one has but with judgments of what one can do with whatever skills one possesses" (1986, p. 391). Bandura and most other selfefficacy researchers have also recognized that this construct is sensitive to environmental phenomena and is situationally dependent; however, many studies have not operationalized self-efficacy measures to reflect this situationality. Consequently, self-efficacy may have been measured more like a trait than a construct with more statelike qualities. Hence, for this initial study, the aim was to better answer the question: How situational is situational self-efficacy? Thus, survey data for general self-efficacy (GSE) was collected at four points during a five-week science project (including the pre- and posttest administered two weeks prior and after), while a measure of situational self-efficacy (SSE) was collected before and after critical learning events at 14 points in time within the five-week project itself. Both surveys were based on the Motivated Strategies for Learning Questionnaire (MSLQ), with slight variation in wording to distinguish between more general feelings of efficaciousness ("courses") with those that are situational ("lessons"). Participants were 186 early high school science students enrolled in a five-week project at Parramatta Marist. Surveys (Qualtrics) were completed online using personal devices. Data was analyzed using the Statistical Package for Social Sciences (SPSS), version 23, and structural equation modeling was undertaken on select general and situational measures using SPSS Analysis of Moment Structures (AMOS) package (version 5, Arbuckle, 2003). Furthermore, the results of confirmatory factor analyses were subject to multigroup invariance testing. Preliminary findings from one factor and two factor models comparing select pairs of general and situational self-efficacy measures indicate that they are indeed measuring two separate but related phenomena. This finding, albeit preliminary, may ultimately lead to a change in how this construct needs to be measured and a greater understanding of how students build confidence (particularly in relation to interest that is situationally generated) in a PBL environment.

\section{The Development and Validation of a New Assessment Tool-The Concept Recall Test (CRT)}

The idea of developing a reliable, valid, and diagnostic assessment tool that can be administered quickly to measure conceptual knowledge (with the possibility of being automated in the future) was greatly appealing to the school-based research team working within a PBL environment where assessment still relied too heavily on conventional assessment formats with all their inherent problems-despite the focus moving from summative to formative assessment (Bell \& Cowie, 2001; Yorke, 2003) - for example, multiple choice questions (see Glass \& Sinha, 2013). Hence, the aim of this research was to explore the following questions: How can a more timely and diagnostic formative assessment to test student knowledge be developed and tested? And how can technology assist this process? The concept recall test (CRT) offered a potential solution. A CRT requires test takers to freely recall concepts they feel are relevant to a give topic, with raters awarding one point for each correctly recalled concept when matched against a target list. The CRT works on the basis of the spreading activation of knowledge within a learner's semantic networks and on recall and not recognition. Administration of the CRT involves a standardized instruction: "Please write down all the concepts or ideas you have about the following topic: . . . Do not write full sentences; only keywords or bullet points will do." After administration of the test, the concepts are scored manually using a targeted concept list. One mark is assigned for each correct concept with raters only having to look out for correct concepts (not sentences, such as in open-ended test questions).

In all studies conducted to date, the inter-rater reliability has been established across all three commonly used measures to determine agreement between raters: (a) percentage agreement, (b) intraclass correlation coefficient (ICC), and (c) Cohen's kappa. Moreover, across four studies in schools both in Singapore and Australia, the results indicate that the concept recall test is a reliable and valid instrument to measure conceptual knowledge (with both convergent and construct validity being established). The further development of this assessment tool has significant potential in a PBL environment where a reliable measure of student knowledge at a particular moment in time is quite desirous. Additionally, the possible automation of this test in the future may streamline this process, thereby increasing its utility. 


\section{Developing and Validating a Reliable Instrument to Measure the Flipped Classroom}

The "flipped classroom" is a relatively recent constructivistbased approach to teaching and learning whose invention has been attributed to various sources (Mazur, 1991; November \& Mull, 2012; Schultz, Duffield, Rasmuseen, \& Wageman, 2014; Baker, 2000; Lage, Platt, \& Treglia, 2000). In more recent years, the flipped classroom has been popularized through the work of Bergmann and Sams (2012). Presently, there is no valid or reliable measure to ascertain the impact of this approach to learning. Hence, is it possible to establish a reliable instrument that measures the effectiveness of the flipped classroom approach to learning? From the seminal literature available, nine distinct "domains" were established that represented the perceived characteristics of the flipped classroom as presented in the literature and as observed by instructors; these included: homework, technology and collaboration, use of class time, teacher role, engagement, self-efficacy, interest, selfdirectedness, learning extent. For each of these domains, a number of items were composed to determine student perceptions, resulting in a 48-item instrument based on a five-point Likertstyle scale. The participants were 136 senior students in their final year at Parramatta Marist. The survey was completed online using personal devices. The data was analyzed using Statistical Package for Social Sciences (SPSS), version 23, and structural equation modeling to understand the loading on each domain was undertaken using SPSS Analysis of Moment Structures (AMOS) package (version 5, Arbuckle, 2003). To determine testretest reliability, the instrument was administered to students halfway through their final high school year twice, 17 days apart. Concurrent validity of the survey instrument was determined by comparing teacher observations with student judgements. Preliminary findings indicated that this measure is a valid means by which to assess student perceptions of the flipped classroom-at least in this context-and students do rate highly most aspects of this approach. In pursuit of this aim, the validity of this flipped classroom measure is currently being deployed in other schools that utilize the flipped classroom in their year 12 classes. Of course, further investigation is required and future studies could examine whether a well-implemented flipped classroom is more highly valued than a traditional classroom, and whether students learn more and performance is improving.

\section{Achievement Motivation Within a PBL Environment}

The aim of this study is to investigate the question: What is the relationship between achievement motivation, task design, and student academic achievement in a PBL environment? One of the implicit assumptions of motivation research is that there is a direct relationship between motivation and achievement (Pintrich \& De Groot, 1990; Pintrich, Smith, Garcia, \& McKeachie,
1993; Wolters \& Pintrich, 1998; Zimmerman, 2008). Both motivation and learning strategies have been weakly connected to students' academic achievements. Overall, the research findings suggest that the relationships between motivation and learning strategies on the one hand, and achievement on the other, are less straightforward and more complex than anticipated. For this study, a general and situational measure of the development of achievement motivation has been constructed based on the MSLQ (with slight variation in wording similar to that used in the self-efficacy study above). This survey was administered to 185 year 9 students in mid-2016. The data is, at present, being processed, and no preliminary findings are available.

\section{Western Sydney University Study Into "Self, Proxy, Collective Efficacy in a PBL Setting"}

Another current research initiative underway, with Dr. Jose Hanham from Western Sydney University, is looking into the development of efficacy among PBL students. The aim of this study was to address the question: How do students develop confidence beliefs in their own abilities (self-efficacy), in their peers and team members (proxy efficacy), and in the performance of their group (collective efficacy) in a PBL setting? In this study, students were given specified roles in the same group (divided in acquaintance and friendship groups) in three different projects in three different key learning areas (geography, English, and religious studies) and asked to rate how confident they were in themselves, their peers, and the group to perform in their allocated roles. Students were surveyed three times at the beginning, midpoint, and end of three 5-week standalone (not integrated) projects in the three knowledge domains outlined above. Performance data for individual students and groups was also collected throughout the project in each knowledge domain. The data for this study has also been collected, and is currently being processed. It is hoped that this study also might shed light on the development of students' critical beliefs, peer interaction, group dynamics, and the relationship between confidence building and the prediction of performance within a PBL environment.

\section{Conclusion and Recommendations}

While still in their infancy (and requiring a reasonably narrow focus), the current research initiatives have the potential to lead to further incremental improvements within the school, based on solid evidence rather than intuition and observation alone-the main guiding principles behind change up to this point in time. Moreover, such research may offer meaningful contribution to the wider extant literature in educational psychology and constructivist approaches to learning. This is particularly evident when considering the 
preliminary findings on the situational development of selfefficacy and the need for it to be measured in a way that befits the construct's supposedly dynamic and environmentally sensitive nature, particularly in a PBL environment. Likewise, the validation of the concept recall test and (it is hoped) the flipped classroom measure may increase the utility and understanding of both assessment and this newer approach to learning in a technologically rich age.

Additionally, by offering even this limited snapshot, we hope that readers gain an appreciation for the multiplicity of approaches to PBL worldwide; the growing international connections forged between educators, researchers, and PBL institutions; and the notion that innovative and constructivist approaches to learning which are carefully and thoughtfully implemented are no barrier to success (including traditional standardized exit exams); and, furthermore, that problem- and project-based learning and other constructive approaches to learning should be considered effective methods of acquiring knowledge with much greater opportunity for students to develop certain soft skills as by-products.

It has also become evident that it is necessary to pursue more institutional research to help refine the teaching and learning goals and processes where possible and also to understand the effect of this approach to learning on alumni. For example, discussion of a possible longitudinal study of PBL-trained alumni (graduating from 2011 onward) has been raised and is of significant interest to a number of stakeholders.

\section{Limitations}

In offering this overview of the introduction, implementation, evolution, hybridization, and preliminary research into the constructivist instructional models deployed within a secondary (high) school in Australia, we realize there are many aspects to the learning environment at school that cannot be fully articulated or explored here. Furthermore, there are a number of limitations to what the research can reveal on a wider scale both within and beyond this school context.

\section{References}

Alwis, W. A. M., \& O'Grady, G. (2002). One day-one problem at Republic Polytechnic. Paper presented at the $4^{\text {th }}$ AsiaPacific Joint Conference for PBL, Songkhla, Thailand.

Arbuckle, J. L. (2014). Amos (Version 23.0) [Computer Program]. Chicago: IBM SPSS.

Baker, J. W. (2000). The "classroom flip": Using web course management tools to become the guide by the side (Paper 15). Communication faculty publications at Cedarville University, Cedarville, $\mathrm{OH}$. http://digitalcommons.cedarville.edu /media_and_applied_communications_publications/15
Bandura, A. (1986). Social foundations of thought and action: A social cognitive theory. Englewood Cliffs, NJ: Prentice-Hall.

Bell, B., \& Cowie, B. (2001). The characteristics of formative assessment in science education. Science Education, 85(5), 536-553. https://doi.org/10.1002/sce.1022

Bergmann, J., \& Sams, A. ( 2012). Flip your classroom, reach every student in every class every day. Virginia: ASCD and ISTE

Glass, A.L., \& Sinha, N. (2013). Multiple-choice questioning is an efficient instructional methodology that may be widely implemented in academic courses to improve exam performance. Current Directions in Psychological Science, 22(6), 471-477. https://doi.org/10.1177/0963721413495870

Jenkins, L. (2012). Reversing the downslide of student enthusiasm. School Administrator, 5(69), 16-17.

Lage, M. J., Platt, G. J., \& Treglia, M. (2000). Inverting the classroom: A gateway to creating an inclusive learning environment. Journal of Economic Education, 31(1), 30-43. https://doi.org/10.2307/1183338

Mazur, E. (1991). Can we teach computers to teach? Computers in Physics, 5(Jan/Feb 1991), 31-38.

November, A., \& Mull, B. (2012, March 29). Flipped learning: A response to five common criticisms. November Learning, 29. http://novemberlearning.com/educational-resources-for -educators/teaching-and-learning-articles/flipped-learning -a-response-to-five-common-criticisms-article/

Perrenet, J. C., Bouhuijs, P. A. J., \& Smits, J. G. M. M. (2000). The suitability of problem-based learning for engineering education: Theory and practice. Teaching in Higher Education, 5(3), 345-358.

Pintrich, P. R., \& De Groot, E. (1990). Motivational and selfregulated learning components of classroom academic performance. Journal of Educational Psychology, 82(1), 33-40.

Pintrich, P. R., Smith, D. A. F., Garcia, T., \& McKeachie, W. J. (1993). Reliability and predictive validity of the Motivated Strategies for Learning Questionnaire (MSLQ). Educational and Psychological Measurement, 53(3), 801-813.

Rotgans, J. I., O'Grady, G., \& Alwis, W. A. M. (2011), Introduction: Studies on the learning process in the oneday, one-problem approach to problem-based learning. Advances in Health Sciences Education, 15(4), 443-448.

Savery, J. R., (2006), Overview of problem based learning: Definitions and distinctions. Interdisciplinary Journal of Problem-based Learning, 1(1), 9-20.

Schmidt, H. G., van der Molen, H. T., te Winkel, W. W. R., \& Wijnen, W. H. F. W. (2009). Constructivist, problembased learning does work: A met-analysis of curricular comparisons involving a single medical school. Educational Psychologist, 44(4), 227-249.

Schultz, D., Duffield, S., Rasmuseen, S. C., \& Wageman, J. (2014). Effects of the flipped classroom model on student 
performance for advanced placement high school chemistry students. Journal of Chemical Education, 91(9), 13341339. https://doi.org/10.1021/ed400868x

Tawfik, A. A., \& Lilly, C. (2015). Using a flipped classroom approach to support problem-based learning. Technology, Knowledge and Learning, 20(3), 299-315. https://doi .org/10.1007/s10758-015-9262-8

Wolters, C., \& Pintrich, P. R. (1998). Contextual differences in student motivation and self-regulated learning in mathematics, English, and social studies classrooms. Instructional Science, 26(1), 27-47.

Yorke, M. (2003). Formative assessment in higher education: Moves towards theory and the enhancement of pedagogic practice. Higher Education, 45(4), 477-501. https://doi.org /10.1023/A:1023967026413

Zimmerman, B. (2008). Investigating self-regulation and motivation: Historical background, methodological developments, and future prospects. American Educational Research Journal, 45(1), 166-183.

Adam Hendry is currently the assistant principal (curriculum) at Parramatta Marist High in Sydney, Australia. He holds a bachelor of arts in education (1999) and a master's degree in ancient history (2005) - both conferred by Macquarie University, Australia. Since 2008, he has been involved in the implementation, practice, and refinement of project- and problem-based learning at Parramatta Marist across all disciplines. In 2015, he commenced doctoral studies into self-efficacy in a PBL environment under Professor Dr. Henk Schmidt at Erasmus University, Rotterdam, Netherlands, co-supervised by Assistant Professor Dr. Jerome Rotgans at the Lee Kong Chian School of Medicine, Nanyang Technological University, Singapore. Adam has taught in schools in the United Kingdom, the Netherlands, and Australia; and has presented at and participated in national and international conferences and symposia on PBL.

Gavin Hays has been at the forefront of the pedagogical change in his former role as assistant principal (curriculum) at Parramatta Marist from 2012 to 2016, specifically in the areas of PBL, flipped learning, and STEM. Currently, he now works with Catholic Education in the Diocese of Parramatta as a learning leader to support schools as they navigate change in implementing contemporary learning pedagogies. Furthermore, he has been involved in a number of international training opportunities within the United States, Singapore, and Finland. He is an accredited PBL trainer within the New Tech Network and is recognized as a problem crafter by Republic Polytechnic, Singapore. He is currently undertaking a doctoral study on contemporary assessment measures studies under Professor Dr. Henk Schmidt at Erasmus University, Rotterdam, Netherlands, co-supervised by Assistant Professor Dr. Jerome Rotgans at the Lee Kong Chian School of Medicine, Nanyang Technological University, Singapore.

Kurt Challinor is a secondary history and religion teacher working as an education officer for religious education in the Catholic school's office in the Diocese of Lismore in New South Wales. He has played key roles in schools (including Parramatta Marist) to support the introduction of innovative pedagogical approaches such as project- and problem-based learning and the flipped classroom through consultation and the facilitation of professional learning for teachers and school leaders. Kurt has presented on pedagogy at conferences in the United States, Finland, and Switzerland, and he is currently undertaking doctoral studies with a research focus on the flipped classroom under Professor Dr. Henk Schmidt at Erasmus University, Rotterdam, Netherlands, cosupervised by Assistant Professor Dr. Jerome Rotgans at the Lee Kong Chian School of Medicine, Nanyang Technological University, Singapore.

Daniel Lynch is currently the deputy principal at Newman College, Perth, Western Australia, a K-12 coeducational school. Between 2013 and 2016 Lynch was a senior school academic and pastoral coordinator at Parramatta Marist High School, Sydney, Australia. Prior to teaching English and history at Parramatta Marist in 2012, Daniel received a bachelor of secondary education (humanities and social sciences) degree with honors at the University of Sydney. In 2014, he completed a master of education (leadership and management) at the University of Sydney and in the same year commenced a master of theology (religious education) through the University of Newcastle. In late 2015, Daniel began doctoral studies into achievement motivation and the use of project-based learning pedagogy in secondary schools under the supervision of Professor Dr. Henk Schmidt at Erasmus University, Rotterdam, Netherlands, co-supervised by Assistant Professor Dr. Jerome Rotgans at the Lee Kong Chian School of Medicine, Nanyang Technological University, Singapore. 